\title{
Imagens Dinâmicas: seus elementos conceituais, elementos gráficos e a participação do leitor
}

\author{
Dynamics images: conceptual elements, graphics elements and reader \\ participation
}

Renata G. Wanderley

imagens, ação, metodologia, análise

Este artigo trabalha com as imagens dinâmicas discutindo seu processo de representação gráfica. Para isso, identifica em uma amostragem de ilustrações seu conteúdo informacional e seus elementos gráficos e observa a participação do leitor em sua compreensão. Como estratégia de atuação apresenta uma proposta de metodologia de pesquisa, fundamentada na descrição livre de uma imagem, para dialogar diretamente com a mesma, e na classificação das informações observadas em parâmetros, no caso os de Wanderley (2006), elementos bases pré-estabelecidos.

image, action, methodology, analysis

This article works with the dynamic images arguing its process of graphical representation. For this, it identifies in an illustration sampling its content and its graphical elements and observes the participation of the reader in its understanding. As performance strategy it presents a proposal of methodology of research, based on the free description of an image, to dialogue directly with the same one, and in the classification of the information observed in parameters, in the case of Wanderley (2006), the elements bases already established.

\section{Introdução}

O entendimento de uma imagem dinâmica é muito mais do que vê-la. Sendo imagem dinâmica a representação imagética cuja informação principal é uma ação e/ou um movimento, a sua mensagem não só é resultado do apresentado nela, seu conteúdo informacional e gráfico, mas também do que seu leitor identifica e compreende. A ação pictórica (representada por elementos pictóricos) na realidade não acontece no material de expressão (a ação não está acontecendo), mas ela é percebida e visualizada pelo observador (vista mentalmente).

As informações apresentadas na mensagem sugerem, dão dicas sobre a ação, pois sendo caracterizada, como apresenta Wanderley (2004 e 2006) e discute Arnheim (2000), como dinâmica (mudanças) e temporal (com passagem do tempo e sequencialidade de eventos), não pode ser representada em sua totalidade. Além disso, a ação não tem uma forma visualmente definida, uma estrutura física que representa o seu conteúdo. Ao contrário, por exemplo, das formas geométricas, uma ação não é definida por uma forma, mas por um conjunto de informações e efeitos.

Tudo isso demonstraria a impossibilidade de uma imagem expressar uma ação, já que as propriedades de uma (a linguagem gráfica) contrariaria as características da outra (a ação). Entretanto, mesmo entendendo que uma representação imagética não captura uma ação em

R. G. Wanderley. 2015. Imagens Dinâmicas: seus elementos conceituais, elementos gráficos e a participação do leitor. In: C. G. Spinillo; L. M. Fadel; V. T. Souto; T. B. P. Silva \& R. J. Camara (Eds). Anais [Oral] do $7^{\circ}$ Congresso Internacional de Design da Informação/Proceedings [Oral] of the 7th Information Design International Conference | CIDI 2015 [Blucher Design Proceedings, num.2, vol.2]. São Paulo: Blucher, 2015. ISSN 2318-6968, DOI 10.5151/designpro-CIDI2015-cidi_80 
si, diante de inúmeras imagens se percebe personagens agindo e objetos se movendo, pois as qualidades bidimensionais, estáticas e atemporais das imagens têm um caráter teórico e conceitual, podendo ser superadas na prática.

Twyman (1985) argumenta que a representação gráfica acontece através do interrelacionamento do conteúdo informacional (a ideia), das formas de representação (modo de representação e de organização) e do usuário (o público alvo), entre outros fatores. Camargo (1998) afirma que é preciso se preocupar não só com o que a imagem representa, mas também como ela o faz. Três estudiosos das abordagens de percepção e representação visual, Rudolf Arnheim (abordagem gestaltista), Ernest Gombrich (abordagem construtivista) e Nelson Goodman (abordagem simbolista), indicam a necessidade da preocupação e trabalho com três aspectos fundamentais: o conteúdo gráfico (forma de expressão), segundo Arnheim e Goodman, o conteúdo informacional e o observador, como aponta Gombrich e Goodman.

Com base nestas discussões e argumentações, essa pesquisa tem como pressuposto para o processo representativo três decisões bases: (1) a decisão do que representar, os elementos conceituais identificadores da ideia; (2) a decisão de com representá-los, as formas gráficas que expressam esses elementos; e (3) a decisão de para quem representar - as características do leitor influentes na sua capacidade em identificar e compreender o todo. Esses elementos norteiam as ações para a construção de imagens dinâmicas eficazes.

\section{A metodologia de pesquisa}

Essa pesquisa acredita que o entendimento do processo de representação imagética de ações se inicia com a própria representação, no que ela tem as nos dizer, no que elas nos transmitem. E a partir delas discutir as referências para analisá-las, experimentá-las, modelálas e finalmente compreendê-las. Assim, é proposto trabalhar diretamente com as imagens num discurso que permita o diálogo entre elas e os observadores. Busca como resultado desse trabalho os seus padrões representativos (como e o que vem comumente sendo utilizados para representar as ações), suas possibilidades de expressão e os problemas apresentados por elas, demonstrando a sua aceitação enquanto veículo de representação.

Essa pesquisa tem um caráter descritivo e analítico, buscando a identificação de elementos bases e o estabelecimento de suas relações em imagens dinâmicas. Como métodos de procedimento envolve o funcionalista ao analisar a função das partes (os elementos conceituais e gráficos para expressar o todo (as ações) e o método comparativo quando confronta as diversas imagens (composição e problemas). Trabalha como técnica a análise de conteúdo através da descrição objetiva, sistemática e quantitativa do conteúdo dos materiais. Os parâmetros de análise são os elemento conceituais (movimento, participantes, trajetória, velocidade e frequência), e gráficos (representações postural, contextual, esquemática, por movimentos múltiplos e por imagens sequenciais) de Wanderley (2004 e 2006).

A amostragem foi probabilística simples com 40 imagens dinâmicas classificadas em três categorias: pintura, fotografia e desenho. Cada imagem foi individualmente descrita de forma verbal pelos pesquisadores e suas informações classificadas segundo os parâmetros de Wanderley (2004 e 2006) em uma tabela resumo. Após a análise das imagens dinâmicas, uma discussão comparativa entre os resultados individuais foi realizada, seguidamente com a apresentação do resultado geral da análise.

\section{A pesquisa analítica}

Como a análise de toda a amostragem é muito extensa são apresentadas literalmente apenas sua aplicação em duas imagem para exemplificação do processo. As imagens exemplos foram escolhidas por se caracterizarem por três propriedades diferentes: período de veiculação, função e tipologia, demonstrando que o problema das imagens dinâmicas não se restringe a nenhuma delas. 


\subsection{A análises exemplo}

\section{Imagem 01}

A primeira imagem (figura 1) é uma pintura cuja representação de uma ação é a sua maior manifestação. A ação da personagem dá significado e expressão a obra. Com observação direta, percebe-se seu conteúdo: uma moça sentada penteando com um pente seus longos cabelos. Esse conteúdo é transmitido pelo pintor e compreendido pelo observador por meio de informações gráficas e conceituais.

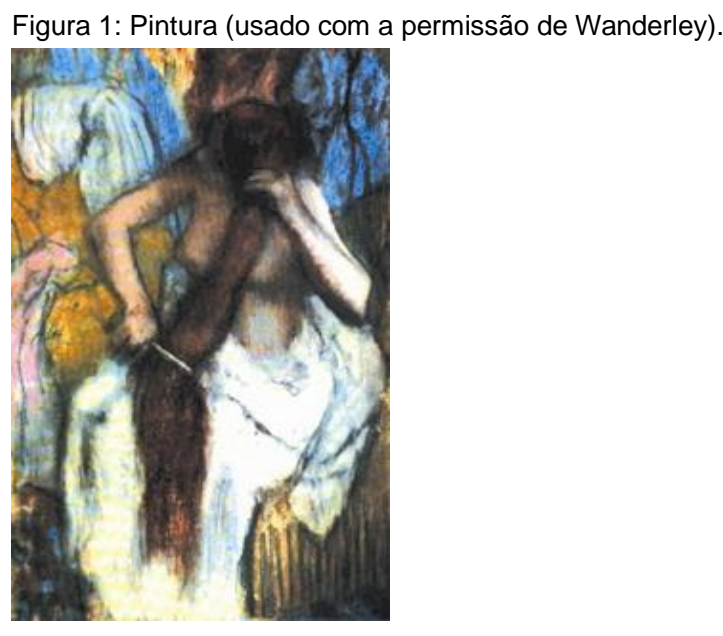

Essa obra apresenta a ação da personagem a partir de um só momento da ação, como um congelamento. Representa todas as informações, as características observadas neste momento específico. Utiliza, com isso, a postura resultante do movimento como a principal forma de representação: rosto um pouco deslocado para a direta e para baixo, braço esquerdo flexionado, mão esquerda próxima à cabeça fechada sobre todo o volume do cabelo, braço direto semiflexionado, mão direta segurando um pente posicionado no meio do comprimento do cabelo. Por ser uma necessidade da ação, as posturas são uma forma bastante comum para representá-la. Esse recurso gráfico nos apresenta um dos principais elementos conceituais das ações, os movimentos realizados para sua execução. Nesta obra, a ação, embora seja representada apenas pela postura da personagem, não ocorre apenas com a demonstração dos movimentos, mas também pelos seus participantes. O agente executor da ação, a moça; o paciente (quem sofre a ação), o cabelo; e o objeto (instrumento da ação), o pente são informações do mesmo modo primordiais para apresentá-la. As consequências da ação também trabalham para expressá-la. A homogeneidade (forma mais definida) do cabelo acima da mão esquerda e a desarmonia (forma menos definida e compacta) dos fios abaixo desta demonstram o resultado dos movimentos, também a partir do posicionamento corporal dos cabelos. Assim, toda a mensagem da obra é transmitida pelo artista com a forma postural de representação e com os elementos conceituais da ação, os participantes, os movimentos e sua consequência. No entanto, todas essas informações não têm valor representacional sem a participação do observador. Ele é o responsável em ver, perceber, interligar e identificar as informações, compreendendo a ação. Se as informações apresentadas nada narram ao observador, mesmo sendo pertinentes à ação, não a representam. Na Tabela 1 são apontados os parâmetros de Wanderley (2006) para imagem 1.

\begin{tabular}{l|l}
$\begin{array}{l}\text { Tabela 1: Análise da pintura } \\
\text { Parâmetros }\end{array}$ & Características na imagem \\
\hline Mensagem Básica & Uma moça sentada penteando com um pente seus longos cabelos \\
\hline Informações conceituais & $\begin{array}{l}\text { Movimento } \\
\text { Participantes: agente, paciente e objeto } \\
\text { Consequência }\end{array}$ \\
\hline Informações gráficas & Um momento da ação \\
& Representação postural \\
\hline Participação do leitor & $\begin{array}{l}\text { Identificação das informações gráficas e conceituais. } \\
\text { Associação das informações com a ação específica. } \\
\end{array}$ \\
& Visualização da ação. \\
\hline
\end{tabular}




\section{Imagem 02}

A segunda imagem (figura 2) é uma fotografia de um pião sobre um espelho tirada por um autor desconhecido. Tem como sensação máxima o movimento. A ação executada pelo personagem é a expressão artística e a mensagem da fotografia, cujo conteúdo básico é o deslocamento espiral de um pião. Este parece ser facilmente percebido pelo observador devido aos recursos gráficos e elementos conceituais utilizados.

Figura 2: Fotografia (usado com a permissão de Wanderley).

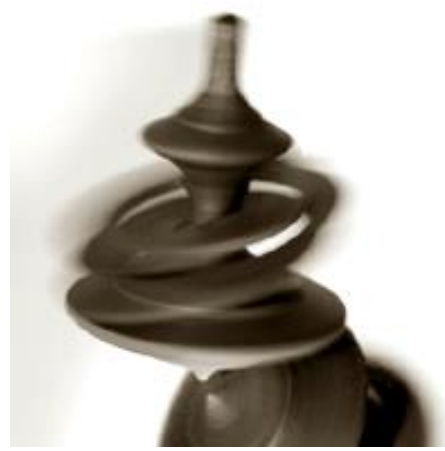

Ao contrário da imagem anterior, esta apresenta momentos múltiplos da ação em uma única imagem. Sua representação acontece principalmente por um recurso gráfico chamado por essa pesquisa de "embaçamento". Algumas posições espaciais de parte do personagem (alguns momentos) são representadas com nitidez pequena, estando embaçadas, e um dos momentos, com alta nitidez, por ser considerado o momento base. Este recurso gráfico tem a capacidade de transmitir a sensação movimento e expressar a velocidade da ação, pois demonstra o efeito provocado pelo deslocamento veloz do personagem. Quanto maior a velocidade do movimento do participante menos nitidez ele adquire devido à dificuldade em observar e identificar suas formas. As posturas das partes do personagem também expressam (mais diretamente) o movimento da ação, o deslocamento espiral. Já a apresentação de vários momentos da ação ajuda na identificação da trajetória realizada pelo personagem, quando demonstra o caminho percorrido através das diversas posições do agente, e menos diretamente, a frequência repetitiva de seus movimentos ao demonstra diversas vezes 0 mesmo movimento.

Enfim, essa ação pictórica é caracterizada por seu participante agente, o pião; seu movimento, o deslocamento; sua trajetória em espiral; sua velocidade significativa e a frequência repetitiva de seus movimentos, elementos conceituais representados por posturas, embaçamento e por momentos múltiplos. Tudo isso depende do observador perceber todas as informações, associá-las entre si e a ação representada. Sem a participação do observador em compreender a mensagem criada pelo fotografo, ela não acontece nem comunica nada. $\mathrm{Na}$ Tabela 2 são apontados os parâmetros de Wanderley (2006) para imagem 2.

Tabela 2: Análise da fotografia

\begin{tabular}{l|l} 
Parâmetros & Características na imagem \\
\hline Mensagem Básica & Um pião rodando \\
\hline Informações conceituais & Movimento \\
& Participante agente \\
& Velocidade \\
& Trajetória \\
& Frequência \\
\hline Informações gráficas & Vários momentos da ação \\
& Representação postural \\
& Representação esquemática: embaçamento \\
\hline Participação do leitor & Identificação das informações gráficas e conceituais \\
& Associação das informações com a ação específica \\
& Visualização da ação \\
\hline
\end{tabular}




\subsection{Discussão dos Resultados}

Por meio dos resultados apresentados na tabela 04, observamos que o movimento é o elemento conceitual mais expressivo das ações, sendo representados em todas as imagens, independente de suas características. Os participantes também são informações bastante presentes nas representações de ações, estando fortemente ligados a seu conceito. Destacase o participante agente, encontrado em $97,5 \%$ das imagens da pesquisa, esse resultado pode ter sido influenciado pelas ações específicas expressas nas imagens. A trajetória é outra informação conceitual presente em mais da metade das representações imagéticas de ações. No entanto, essa representação acontece, algumas vezes, de forma pouco direta, pela interpretação do observador e pelo contexto geral, como por exemplo, a figura 01 exemplificada. A velocidade e a frequência dos movimentos tem participação mediana na conceituação das ações das imagens dessa análise. A frequência, como a trajetória, também é percebida em muitos casos pela interpretação do observador ao entender a necessidade de repetição dos movimentos. Já com a velocidade, percebe-se que embora seja uma característica de toda ação, só torna-se um elemento especificador pictórico quando tem uma intensidade significativa no real (velocidade alta ou pelo menos significativa). As consequências das ações, desde uma sutil fumaça, uma nova postura ou até uma deformação, é uma informação presente nas ações pictóricas. A causa das ações, se devido ou não à sua importância para poucas, quase não é utilizada para caracterizá-las. Com base na comparação entre as categorias de imagens, apenas a trajetória é uma informação que tem uma variação relevantes como elemento conceitual, pouco encontrada na pintura, mas apresentada nos desenhos e fotografias.

Para as informações gráficas, nenhuma forma de representação teve a utilização plena como o elemento conceitual movimento. A representação postural, contudo, é o modo mais comum de expressar graficamente as ações em qualquer categoria de imagens, já que as postural são uma "exigência" para sua realização. O contexto, enquanto ambiente dentro da imagem, e não no qual ela está inserida, é um fator relevante para se compreender as ações. Por caracterizar a ação no geral, pode fornecer informações adicionais as representadas, como a trajetória da ação de andar em que a direção dos braços e pernas do participante e o contorno do local onde ele caminha pode indicá-la. Os elementos esquemáticos é razoavelmente uma forma de expressar ações $(50 \%)$ por dar uma forma as informações que, muitas vezes, não acontecem (as fumaças e linhas, por exemplo) ou não são demonstradas (trajetórias) no real. Têm maior destaque para os desenhos, restringindo sua participação nas fotografias através do recurso gráfico de embaçamento (efeito produzido pela própria máquina fotográfica). A representação de vários momentos da ação não é uma escolha muito comum para as imagens dinâmicas, tendo maior destaque (30\%) para as representações por momentos múltiplos (vários momentos em uma única ilustração), principalmente nos desenhos das histórias em quadrinhos. A simbolização dos sons resultantes das ações são elementos não valorizados na representação de ações, tendo pouca participação.

E a participação do observador está presente no processo comunicacional de todas as imagens. Sua atuação na visualização, percepção e associação das informações é indispensável para a compreensão da mensagem. O equilíbrio entre o repertório conceitual e imagético de ações do observador e as informações apresentadas na imagem é o principal princípio do processo representativo e a preocupação base para todo projeto gráfico.

Diante de dessa discussão e da metodologia utilizada para analisar as imagens dinâmicas, percebe-se que, em acordo com os parâmetros de Wanderley (2006), as ações pictóricas são resultados não só de formas gráficas que as expressam, mas também de conceitos e elementos dinâmicos que as caracterizam e diferenciam, e da participação do leitor que reconhece as informações e compreende as ações. Esses elementos dinâmicos são principalmente os movimentos necessários para a realização das ações, os participantes, que tanto executam com sofre ou auxiliam sua execução, a trajetória, velocidade e frequência do movimento, bem como as consequências e causas de toda a ação. $E$ as principais formas de representação gráfica de ações e desses elementos dinâmicos são as posturas e sons resultantes das ações, o contexto em que ela ocorre e os elementos e recursos esquemáticos (setas, linhas e embaçamento). Além disso, a representação de um momento da ação ou de vários deles (momentos múltiplos) são opções para sua representação pictórica. Assim, o 
entendimento das imagens dinâmicas deve englobar os próprios conceitos de ações, as informações que as caracterizam, diferenciam e especificam; as possibilidades gráficas de representação, como é possível expressar certas informações num meio gráfico; a participação do observador, a interferência de suas características físicas, psicológicas, culturais, educacionais, entre outras, na compreensão e percepção das informações; a necessidade e dependência do equilíbrio entre o produzido e o aceito, conhecido e compreendido pelo observador da mensagem. A Tabela 3 apresenta os resultados gerais dos parâmetros de Wanderley (2006) para toda a amostragem.

Tabela 3: Resultados gerais

\begin{tabular}{|c|c|c|c|c|c|}
\hline \multicolumn{2}{|c|}{ Informações/ tipo de imagem } & \multirow{2}{*}{$\begin{array}{l}\text { Pintura } \\
13 \\
\end{array}$} & \multirow{2}{*}{$\begin{array}{l}\text { Fotografia } \\
14\end{array}$} & \multirow{2}{*}{$\begin{array}{l}\text { Desenho } \\
13\end{array}$} & \multirow{2}{*}{$\begin{array}{l}\text { Total } \\
40\end{array}$} \\
\hline \multirow{8}{*}{$\begin{array}{l}\text { Informações } \\
\text { conceituais }\end{array}$} & Movimento & & & & \\
\hline & $\begin{array}{l}\text { Participante: } \\
\text { Agente, Paciente e Objeto }\end{array}$ & $\begin{array}{l}12 \\
03 \\
03\end{array}$ & $\begin{array}{l}14 \\
02 \\
04\end{array}$ & $\begin{array}{l}13 \\
05 \\
03\end{array}$ & $\begin{array}{l}39 \\
10\end{array}$ \\
\hline & Velocidade & 03 & 07 & 04 & 14 \\
\hline & Frequência & 04 & 04 & 04 & 12 \\
\hline & Trajetória & 05 & 13 & 10 & 28 \\
\hline & Direção e sentido & 07 & 09 & 10 & 26 \\
\hline & Causa & 01 & 01 & 01 & 3 \\
\hline & Consequência & 04 & 06 & 09 & 19 \\
\hline \multirow{6}{*}{$\begin{array}{l}\text { Informações } \\
\text { gráficas }\end{array}$} & Postura & 12 & 10 & 11 & 33 \\
\hline & Contexto & 07 & 10 & 07 & 24 \\
\hline & Ilustrações sequenciais & 00 & 00 & 01 & 01 \\
\hline & Momentos múltiplos & 02 & 02 & 08 & 12 \\
\hline & Som & 00 & 00 & 03 & 03 \\
\hline & Elementos esquemáticos & 05 & 04 & 11 & 20 \\
\hline \multicolumn{2}{|c|}{ Participação do leitor } & 13 & 14 & 13 & 40 \\
\hline
\end{tabular}

\section{Considerações finais}

Este artigo discutiu a representação gráfica de ações, apresentando uma proposta de metodologia de pesquisa baseada no trabalho livre e direto com as próprias imagens dinâmicas, no que elas podem nos ensinar. Essa metodologia demonstrou ser coerente e ajudou a tentar responder os questionamentos propostos e a atingir os objetivos desejados, pois seguiu um caminho lógico e orientou as ações para o entendimento das imagens dinâmicas. Com a descrição detalhada das imagens como base nos recursos gráficos empregados, nos elementos conceituais utilizados e na significação dada pelo observador, é possível afirmar que os três grupos de parâmetros apresentados (informações conceituais, informações gráficas e participação do leitor) de Wanderley (2006) são elementos fundamentais na expressão gráfica de ações.

Embora a amostragem utilizada nesta pesquisa não abranja todo o universo das imagens dinâmicas, ela é capaz de posicionar os parâmetros fundamentais e ser ponto de partida para a compreensão da imagens dinâmicas.

Estamos conscientes, contudo, que apenas esboçamos uma possibilidade de metodologia para a análise de imagens dinâmicas e mapeamos alguns padrões representativos e possibilidades de expressão de ações. Ainda que haja muito a ser estudado e explorado, buscamos com a metodologia proposta e os aspectos discutidos uma conclusão mais abrangente através da construção gradual e coerente do conhecimento com observação e identificação das informações relevantes para a representação gráfica de ações.

Por fim, espera-se que este estudo contribua para o corpo de conhecimentos sobre pesquisa em representação de ação e movimento no âmbito da linguagem gráfica e design da informação. E Colabore para o desenvolvimento de interesse de investigações nesta temática ou metodologia por outros pesquisadores.

\section{References}

ARNHEIM, R. 2000. Arte e Percepção Visual: uma psicologia da visão criadora. 12 ed. São 
Paulo: Livraria Pioneira Editora.

CAMARGO, L. 1998. A relação entre imagem e texto na ilustração de poesia Infantil. Campinas GOMBRICH, E.H. 1995. Arte e Ilusão. 3.ed. São Paulo: Martins Fontes.

GOODMAN, N. 1976. Languages of art, an approach to a theory of symbols. Inglaterra: Oxford U.P,

TWYMAN, M. 1985. The graphic presentation of language. Information Design Journal. Londres, v.3. p.1-22.

WANDERLEY, R.G. 2004. Parâmetros para a representação gráfica de ações. In: 6 Congresso Brasileiro de Pesquisa e desenvolvimento em Design. São Paulo, 13 a 16 de outubro, 2004. Anais do 6ํㅡㄹ Congresso Brasileiro de Pesquisa e Desenvolvimento em Design. São Paulo: FAAP.

WANDERLEY, R.G. 2006. Uma Abordagem para a Representação Gráfica de 'Ações

Dinâmicas'. Dissertação de mestrado não publicada. Departamento de Design. Universidade Federal de Pernambuco, Pernambuco.

\section{Sobre a autora}

Renata Garcia Wanderley, doutora, UFPE, Brasil, <renatagw@hotmail.com> 